\title{
JUURNAL.RU
}

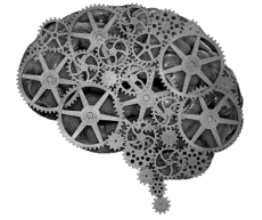

COMPANY GROUP "INTELLEKT"

Ваничева Е.А., Никифорова С.В. ФГБОУ ВО «Санкт-Петербургский государственный экономический университет»

(СПбГЭУ)

Санкт-Петербург, Россия

doi: 10.18411/lj2016-9-2-02

idsp 000001: lj2016-18-2-02

\section{Обоснование выбора инструментов маркетинга на различных этапах жизненного цикла стартапа}

В настоящей статье, посвященной формированию современной системы маркетинговых инструментов по этапам жизненного цикла стартапа, мы остановимся на следующих вопросах: определение понятия «стартап», формирование модели жизненного цикла стартапа, разработка маркетинговых инструментов по этапам жизненного цикла стартапа.

\section{Определение понятия «стартап»}

В научной литературе первое определение стартапа появилось в 2014 году у Эрика Риса: «Стартап - это вновь созданная организация, которая занимается разработкой новых товаров и услуг в условиях чрезвычайной неопределенности»[1].

Стив Бланк и Боб Дорф в своей работе «СтратUP. Настольная книга основателя» дают иное определение: «Стратап - временная организация, созданная для поиска ответов на вопрос: что делает бизнес-модель воспроизводимой и масштабируемой»[2].

Можно также рассмотреть определения понятия стартап, сформулированные в следующих источниках:Интернет-порталInvestopedia[3], Пол Грэм[4], агентство по инновациям[5].

Как видно, трактовки понятия «стартап» можно условно разделить на два класса: с учетом инновационной идеи, лежащей в основе стартапа; без учета инновационной идеи, только лишь на основании оценки динамики, возраста и 
оборотов. Можно сделать общий вывод, что оба подхода -по отдельности не дают объективного представления стартапа.

С учетом анализа нами предложено определение в краткой и полной формах:

1 определение (краткое): Стартап - это временная структура, объединяющая людей, преследующих общую цель - выработка и быстрая реализация в виде рентабельного продукта или услуги массового использования жизнеспособной инновационной идеи.

2 определение (полное): Стартап - это временная организационная структура, объединяющая в себе небольшую группу увлеченных одной инновационной идеей лиц, целью функционирования которой является быстрая разработка при постоянном взаимодействии с потенциальным покупателем, используя гипотезы и доказательства, продукта или услуги с рентабельной бизнес-моделью, и вывод данного продукта или услуги в массовое использование.

\section{Этапы жизненного цикла стартапа}

Следующим вопросом настоящего исследования является обоснование модели жизненного цикла с учетом этапов жизненного цикла.

Классическое, устоявшееся определение товара по Ф. Котлеру - это «все, что может удовлетворить потребность или нужду и предлагается рынку с целью привлечения внимания, приобретения, использования или потребления»[6].

Для формирования представления об инновационном товаре, приведем пример определения одной из его групп, а именно высокотехнологичного продукта, которое представлено в диссертации Бейгул В.Н.: «Это радикально новый продукт (родовой или новой продуктовой категории) или новый продукт, используемый наряду с традиционными, но обладающий уникальными свойствами, по которым у существующих производителей недостаточно опыта производства, менеджмента и маркетинга»[7].

Что же касается «стартап-товара», то его главное отличие от инновационного товара - скорость разработки и захвата рынка. Упрощенно можно сказать, что быстрый инновационный продукт, как правило - это «стартап-продукт». 
При построении модели жизненного цикла стартапа авторы основывались на следующих ее видениях, предложенных в литературе: фонд развития содействия предпринимательства[8], информационно-аналитическийІТ-портал [9], Forbes.ru [10] Андрей Парабеллум и Денис Запиркин «Развитие бизнеса» [11]международное исследование успехов и неудач стартапов «StartupGenomeReport» [12], Эрик Рис «БИЗНЕС С НУЛЯ» [1], Стив Бланк [2].

Подводя общий итог рассмотренным наиболее популярным подходам к построению и определению этапов жизненного циклов стартапов, можно увидеть, что в современном мире при определении жизненного цикла стартапа мы должны постоянно учитывать связь стартап-компании с продуктом, который лежит в основе любого стартапа: именно этот продукт и является реализацией начальной инновационной идеи и продажи его определяют, в том числе, динамику развития стартапа.

Таким образом, составим жизненный цикл стартапа из восьми основных этапов. Идея->Пробные продукт-> Апробация->Корректировка->Готовый продукт->Выход на рынок->Масштабирование.

1 этап. Идея (гипотеза).Цель: определение сегмента рынка, где будет функционировать стартап, с последующим формированием цели и общего проектного видения существования стартапа.

2 этап. Пробная модель.Цель: создание прототипа продукта с разработкой проекта маркетинговой стратегии.

3 этап. Апробация.Цель: первичная апробация продукта на рынке.Здесь мы впервые выпускаем продукт «в свет», показывая его потребителю (определенной заранее целевой аудитории).

4 этап. Корректировка.Цель: корректировка продукта по результатам пробных выходов на рынок.

5 этап. Готовый продукт.Цель: разработка полностью готового продукта, проработка всех сторон развития бизнеса, включая финальную корректировку маркетинговой стратегии.

6 этап. Бизнес-модель.Цель: создание бизнес-модели.

7 этап. Финансирование.Цель: финансовое обеспечение развития проекта.На этом этапе происходит выход продукта на рынок с реализацией 
второй части маркетингового плана, поиском основных инвесторов и массовыми продажами продукта.

8 этап. Масштабирование.Цель: масштабирование проекта, выход на новые рынки.На этом этапе возможна реализация стратегического плана развития бизнеса, с выполнением третьей части маркетингового плана, захватом новых рынков, ресегментации рынков, но это все уже не часть развития стартапа, а развитие крупного бизнеса на биржевом рынке.

\section{Инструменты маркетинга по этапам жизненного цикла стартапа}

Исходя из сформированной модели жизненного цикла стартапа и определим технологии по этапам жизненного цикла следующим образом (Таблица 1).

Обоснуем более подробно приведенные соответствия.

Так как основная задача первого этапа - это формирование работоспособной инновационной идеи, то здесь необходимы соответствующие инструменты, которые позволяют с одной стороны генерировать новые жизнеспособные идеи, а с другой - дать четкое представление о потребители продукта.

Основная задача второго этапа - разработка пробной модели, соответствующего ей пробного маркетингового плана. Здесь понадобятся маркетинговые инструменты создания и апробации модели, формирования интереса у будущих потребителей, а также инструменты, которые позволят соотнести модель и прогноз ее развития с конкурентами.

Третий этап характеризуется апробацией пробного продукта с выработкой пожеланий по его доработки, в том числе на основе пожеланий и замечаний конечного потребителя. Здесь понадобятся инструменты и технологии для формирования пробной аудитории потребителей.

Таблий 1

Соответствие инструментов маркетинга этапам жизненного ичикла стартапа

\begin{tabular}{|c|c|c|}
\hline $\begin{array}{c}\text { Этап } \\
\text { жизненного } \\
\text { цикла }\end{array}$ & Цель & Инструмент маркетинга \\
\hline & $\begin{array}{c}\text { Определение } \\
\text { сегмента рынка, } \\
\text { формирование } \\
\text { цели и общего } \\
\text { Прдек } \\
\text { (гипотеза) }\end{array}$ & $\begin{array}{c}\text { Краудсорсинг, схема Абеля, латеральный маркетинг } \\
\text { видения. }\end{array}$ \\
\hline $\begin{array}{c}\text { 2. Пробная } \\
\text { модель }\end{array}$ & Создание \\
прототипа & Бенчмаркинг, пробный маркетинг, рыночные эксперименты, \\
минимально целесообразный продукт, обращение к аналогам
\end{tabular}




\begin{tabular}{|c|c|c|}
\hline & $\begin{array}{c}\text { продукта с } \\
\text { разработкой } \\
\text { проекта } \\
\text { маркетинговой } \\
\text { стратегии. }\end{array}$ & \\
\hline 3. Апробация & $\begin{array}{c}\text { Первичная } \\
\text { апробация } \\
\text { продукта на } \\
\text { рынке. } \\
\end{array}$ & $\begin{array}{c}\text { Краудсорсинг, пробный маркетинг, вирусный маркетинг, } \\
\text { маркетинговый евангелизм, модель маркетинга freemium, } \\
\text { игрофикация, система DART, SMM, продвижение сайта и др. }\end{array}$ \\
\hline $\begin{array}{l}4 . \\
\text { Корректировк } \\
\text { a }\end{array}$ & $\begin{array}{c}\text { Корректировка } \\
\text { продукта по } \\
\text { результатам } \\
\text { пробных выходов } \\
\text { на рынок. }\end{array}$ & Латеральный маркетинг, обращение к аналогам, метод Н. Кано \\
\hline $\begin{array}{l}\text { 5. Готовый } \\
\text { продукт }\end{array}$ & $\begin{array}{c}\text { Разработка } \\
\text { полностью } \\
\text { готового } \\
\text { продукта, } \\
\text { проработка всех } \\
\text { сторон развития } \\
\text { бизнеса. }\end{array}$ & $\begin{array}{c}\text { Теория инноваций, нейромаркетинг, тестимониалс, модель } \\
\text { маркетинга freemium, игрофикация, сторителлинг, SMM, } \\
\text { продвижение сайта и др. }\end{array}$ \\
\hline $\begin{array}{c}\text { 6. Бизнес- } \\
\text { модель }\end{array}$ & $\begin{array}{l}\text { Создание бизнес- } \\
\text { модели. }\end{array}$ & $\begin{array}{c}\text { Бенчмаркинг, схема Абеля, дорожные карты, ценообразование на } \\
\text { основе воспринимаемой ценности, карта рынка }\end{array}$ \\
\hline $\begin{array}{c}7 . \\
\text { Финансирова } \\
\text { ние }\end{array}$ & $\begin{array}{c}\text { Финансовое } \\
\text { обеспечение } \\
\text { развития проекта. }\end{array}$ & Теория инноваций, карта рынка \\
\hline $\begin{array}{l}8 . \\
\text { Масштабиров } \\
\text { ание }\end{array}$ & $\begin{array}{l}\text { Масштабировани } \\
\text { е проекта, выход } \\
\text { на новые рынки. }\end{array}$ & $\begin{array}{c}\text { Бенчмаркинг, схема Абеля, нейромаркетинг, теория инноваций, } \\
\text { вирусный маркетинг, тестимониалс, модель маркетинга freemium, } \\
\text { сторителлинг, игрофикация, SMM, интернет-реклама и др. }\end{array}$ \\
\hline
\end{tabular}

Четвертый этап необходим для внесения корректировок в продукт на основе результатов апробации. Здесь можно вновь обратиться к поиску нестандартных решений, например, для удовлетворения определенных потребностей потребителя с помощью разрабатываемого продукта в условиях, когда изначально данный продукт для этого не предназначался.

На пятом этапе происходит вывод продукта на рынок по итогам доработок и необходимо использовать вновь все те типы инструменты маркетинга, которые использовались на третьем этапе.

Основная задача шестого этапа - разработка адекватной бизнес-модели жизни продукта на рынке в условиях конкурентной среды, но с учетом инновационного характера, включающей различные уровни планирования.

На седьмом этапе самым важным является привлечение финансирования со стороны внешних инвесторов, здесь использование инструментов маркетингаприменяют для доказательства инновационного характера, перспективности и жизнеспособности продукта, и анализ карты рынка.

На восьмом этапе происходит полномасштабное развития продаж продукта с основанием новых ниш рынка. Здесь применимы все 
рассматриваемые инструменты маркетинга, так они не только должны обеспечивать продажи, но и дать «задел» на будущее, которое может выразиться, в формировании новой инновационной идеи.

\section{Заключение}

В данной статье на основании рассмотрения понятия «стратап», представленного в иностранной и отечественной литературе сделан вывод об отсутствии единого объективного понятия, которое бы характеризовало стартап как молодую, динамично развивающуюся организацию, построенную на основе инновационной идеи. На основании критического анализа существующих определений, представлено многогранное рассмотрение понятия «стартап» и предложены два определения: в краткой и полной формах.

На основе проведенного анализа существующих моделей жизненных циклов, выявлены их определенные недостатки и авторами построена восьмиуровневая модель жизненного цикла стартапа, содержащая следующие уровни: идея (гипотеза), пробная модель, апробация, корректировка, готовый продукт, бизнес-модель, финансирование, масштабирование.

На каждом уровне (этапе) существуют свои особенности маркетинга стартапов. Представлены маркетинговые инструменты, определенные и обоснованные целями, преследуемыми на каждом этапе. Содержащиеся в анализе маркетинговые инструменты универсальны как с точки зрения взаимодополняющей роли, так и в связи с альтернативными функциями. 


\section{Литература:}

1. Эрик Рис. Бизнес с нуля: Метод LeanStartup для быстрого тестирования идей и выбора бизнес-модели - 3-е изд. - М.: АЛЬПИНА ПАБЛИШЕР, 2014. $-253 \mathrm{c}$.

2. Стив Бланк Стартап: настольная книга основателя/ Стив Бланк, Боб Дорф // Пер. с англ. - 3-е изд. - М.: Альпина Паблишер, 2015. - 616 с.

3. «I» INVESTOPEDIA [Электронный ресурс]. - Режим доступа: http://www.investopedia.com/ - Заглавие с экрана. - (Дата обращения: 17.05.2015).

4. «ToWave» издание о стартапах [Электронный ресурс]. - Режим доступа: http://www.towave.ru/pub/kak-pravilno-obyasnit-chto-takoe-startap.html Заглавие с экрана. - (Дата обращения: 18.05.2015).

5. «АИР» агентство по инновациям и развитию [Электронный ресурс]. Режим доступа: http://www.innoros.ru/publications/interesting/14/startappravilnoe-opredelenie - Заглавие с экрана. - (Дата обращения: 18.05.2015).

6. Котлер, Филип Основы маркетинга/Филип Котлер - М.: Издательство «Прогресс», 1991.

7. Бейгул, В.Н. Маркетирование высокотехнологичных стартапов / Бейгул В.Н. // Дисс. на соиск. уч. степ.к.э.н. - Санкт-Петербург - 2014 - 159 стр.

8. Фонд содействия развитию предпринимательства (EAS) [Электронный pecypc]. - Режим доступа: http://www.eas.ee/ru/nachalo/osnovanie-startapkompanii/zhiznennyj-cikl-startap-kompanii - Заглавие с экрана. - (Дата обращения: 15.07.2015).

9. Интернет-журнал о технологиях [Электронный ресурс]. - Режим доступа: http:/digit.ru/columnists/20130430/401102220.html - Заглавие с экрана. (Дата обращения: 19.07.2015).

10. Интернет-версия журнала Forbse [Электронный ресурс]. - Режим доступа: http://www.forbes.ru/ - (Дата обращения: 28.07.2015). 
11. Андрей Парабеллум, Денис Запиркин, Развитие бизнеса - 2011 - 180 с.

12. StartupGenomeVancouver [Электронный pecypc]. - Режим доступа: http://startupgenome.cc/- Заглавие с экрана. - (Дата обращения: 06.08.2015). 